\title{
Social Well-Being and Pro-Environmental Behavior: A Cross-Lagged Panel Design
}

\author{
Gabriele Prati,, Cinzia Albanesi, and Luca Pietrantoni \\ Department of Psychology \\ Alma Mater University of Bologna, Italy
}

\section{Abstract}

The main aim of this study was to investigate the bidirectional relationship between social well-being and energy conservation behavior as a form of pro-environmental behavior. Participants were 298 undergraduate and master's students at an Italian public university. We applied structural equation modeling with two waves of survey data from a cross-lagged panel design to investigate reciprocal relationships between latent variables representing social well-being and pro-environmental behavior. Results showed that pro-environmental behavior at baseline predicted later social well-being controlling for the effects of baseline social well-being. Conversely, social well-being at baseline predicted subsequent levels of pro-environmental behavior controlling for previous levels of pro-environmental behavior. Results were compared using multi-group invariance testing of paths across gender. These relationships did not differ between men and women. Together, these findings suggest that a bidirectional relationship between social well-being and pro-environmental behavior is supported.

Keywords: cross-lagged panel design, longitudinal studies, pro-environmental behavior, social well-being

\section{Introduction}

Behavioral and lifestyle choices are key to successful adaptation and mitigation of climate change (IPCC, 2014). Previous studies have shed light on a complex multifactorial process that includes personal and social influences on proenvironmental concern and behavior (Gifford \& Nilsson, 2014). For instance, women tend to report stronger environmental concern and behaviors than men (Gifford \& Nilsson, 2014; Hunter et al., 2004; Zelezny et al., 2000). The Intergovernmental Panel on Climate Change estimated that, in developed countries, lifestyle and behavioral changes could reduce energy demand by up to $20 \%$ in the short term

1 Author contact: gabriele.prati@unibo.it 
and 50\% in the long term (IPCC, 2014). Government agencies have encouraged manufacturers to improve the energy efficiency of household appliances. Indeed, much can be done to understand and address those behavioral and lifestyle choices which significantly influence energy consumption. However, in order to reduce the negative consequences associated with climate change, it is necessary to understand the processes that underlie pro-environmental behavior.

The field of conservation psychology has been proposed based on the recognition that the social sciences play a key role in achieving the goal of environmental sustainability (Clayton \& Myers, 2015; Saunders, 2003). The ultimate outcome for conservation psychology research is conservation behavior. Conservation behavior is often perceived to have negative effects on an individual's quality of life: "People, it is argued, are being asked to give up a modern, high-technology existence for an austere, bleak but needed substitute" (De Young, 1990, p. 216). Although conservation behavior can be framed in self-sacrificial terms (e.g., Carmi, 2012), some scholars view well-being and conservation behavior as compatible or complementary (e.g., Brown \& Kasser, 2005; Corral-Verdugo et al., 2011; Dietz et al., 2009; Xiao \& Li, 2011). Suárez-Varela et al. (2016) reported that proenvironmental behavior in itself does not have a negative influence on well-being, suggesting that it can be framed in self-beneficial terms. Indeed, there is evidence that pro-environmental behavior can increase eudaemonic well-being (Venhoeven et al., 2013). Eudaemonic well-being is generally defined as striving to realize one's personal potential (Ryff \& Keyes, 1995). Eudaemonic well-being is thus related to the pursuit of intrinsic goals such as self-actualization, positive close relationships, personal growth, sense of meaning in life, and participation in social communities. This aspect of well-being goes beyond hedonic approaches defined by the simple pursuit of pleasure (e.g., staying away from problems, being happy and relaxed). While there is evidence that hedonic values are negatively related to environmentally relevant attitudes, preferences, and behaviors (Steg, Perlaviciute et al., 2014), we expect that eudaemonic well-being may play a different role when it comes to its relationship with conservation behavior.

The positive relationship between eudaemonic well-being and pro-environmental behavior such as conservation behavior can be inferred from research on pro-social behavior. Pro-social behavior is supposed to have an enduring effect on well-being through different processes, such as giving meaning to life, contributing to a positive self, or providing a social identity (Son \& Wilson, 2012). Pro-environmental behavior is viewed as a form of pro-social behavior (Steg \& de Groot, 2010; Turaga et al., 2010; Venhoeven et al., 2013). Since engaging in pro-social behavior increases well-being if it provides meaning in life (e.g., "doing the right thing"), in their review, Venhoeven et al. (2013) hypothesized that pro-environmental behavior can enhance eudaemonic well-being if such behavior is perceived as a source of meaning in life. 
Published studies on the relationship between well-being and pro-environmental behavior have focused on emotional well-being or psychological (eudaemonic) well-being (e.g., Venhoeven et al., 2013). In his mental health continuum model, Keyes (2002, 2003) conceptualizes three categories of well-being: emotional, psychological, and social. Emotional well-being corresponds to hedonic well-being, while psychological and social well-being represents two forms of eudaemonic well-being. Specifically, psychological well-being refers to the concept of private and personal development and self-realization, whereas social well-being indicates thriving in one's own public, social life. Factor analyses revealed that emotional well-being, psychological well-being, and social well-being formed three correlated but distinct factors (Keyes, 1998). There is evidence of a positive relationship between pro-environmental behavior and psychological well-being (Corral-Verdugo et al., 2011; Ganglmair-Wooliscroft \& Wooliscroft, 2016; Suárez-Varela et al., 2016; Venhoeven et al., 2013). In addition, a link between positive emotions and environmentally responsible behavior has been proposed (e.g., Cloutier et al., 2014; Helliwell, 2014; O'Brien, 2008). Previous studies have shown that psychological factors correlated to well-being such as self-construal, sense of control, values, world views, goals, and felt responsibility (Gifford \& Nilsson, 2014). To our knowledge, no study has investigated the relationship between social well-being and conservation behavior. Although, on one hand, community participation and involvement, and, on the other hand, intentional communities have been related to engagement in pro-environmental behaviors (e.g., Choi, 2008; Sanguinetti, 2012; Stem et al., 2003; Villacorta et al., 2003), we note that these constructs are different from social well-being. Social well-being can be defined as people's appraisal of their social relationships, circumstance, and functioning in social institutions and community (Keyes, 1998; Larson, 1993). There is evidence that men are more likely to have high-level social well-being compared to women (Keyes, 2004). Although pro-environmental behavior and pro-social behavior are different (Nolan \& Schultz, 2015), to some degree they are compatible. Social well-being is relevant for proenvironmental behavior because it has to do with the feeling that one is a vital member of the community, contributing to the common good and believing in the progress and evolution of society. In addition, pro-environmental behavior, like other pro-social behaviors, can enhance the view that one is pursuing the right ends for society and the community, and that his or her actions are valued by society and contribute to the commonwealth (Corral-Verdugo et al., 2011; Suárez-Varela et al., 2016; Venhoeven et al., 2013). This leads us to the first hypothesis of our study:

Hypothesis 1: Conservation behavior will predict social well-being.

Most of the evidence that supports the finding that conservation behavior predicts well-being has been gathered from cross-sectional research designs. Thus, we cannot rule out the possibility that conservation behavior can both affect and be the result of well-being. Theoretical and empirical support for this alternative idea-that well- 
being influences conservation behavior-can be found in research on pro-social behavior. First, there is evidence of a positive feedback loop between pro-social behavior and well-being (Aknin et al., 2012). Corral-Verdugo et al. (2011) also acknowledged the possibility that a positive feedback loop between conservation behavior and well-being may exist. Second, a substantial body of research shows that positive mood states influence pro-social behavior (Carlson et al., 1988). Specifically, the social outlook hypothesis posits that a positive mood associated with a favorable view of one's interpersonal relationships, community, society, or human nature increases the likelihood of pro-social behavior (Carlson et al., 1988). Finally, well-being may have an influence on sustainable consumer behavior (Fröhlich et al., 2012). Therefore, we should expect that social well-being, defined as the appraisal of one's circumstance and functioning in society (Keyes, 1998), might predict conservation behavior, leading to our second hypothesis:

Hypothesis 2: Social well-being will predict conservation behavior.

As stated above, most of the literature on the relationship between well-being and conservation behavior is based on cross-sectional (i.e., correlational) research, which is limited in its ability to identify bidirectional predictive relationships. Moreover, past work has not specifically measured social well-being. To address the limitations of previous studies, we used a longitudinal study and simultaneously took into account cross-lagged (i.e., longitudinal interplay between social well-being and conservation behavior) and concurrent associations (i.e., relationships between different variables measured at the same time), as well as stability of the constructs (i.e., relationships between the same variables measured at two points in time). Another reason why we used a longitudinal design is the risk for common method bias (Podsakoff et al., 2012). Specifically, when participants' reports of their internal states are collected at the same time as their reports of their behavior (as in crosssectional studies), the observed correlations between these two types of variables are likely to be artificially inflated.

As stated earlier, there is evidence that men are more likely to have high-level social well-being compared to women (Keyes, 2004) and that women tend to engage in more environmental behaviors than men (Gifford \& Nilsson, 2014; Hunter et al., 2004; Schultz \& Zelezny, 1999). However, it is unclear whether these gender differences might influence the hypothesized relationships. Therefore, we propose a research question rather than a hypothesis:

Research question: Do the hypothesized relationships differ between men and women? 


\section{Method}

\section{Participants}

Participants were 308 undergraduate and master's students ( 234 women, 74 men) at an Italian public university. At class sessions, after a brief description of the study objectives, students were invited to participate. There were considerably more women than men in our sample because women were concentrated in these degree programs. Students received course credit for their participation. We asked participants to fill out the same questionnaire at Time 1 (T1) and Time 2 (T2). We removed from the sample 10 participants because they failed to complete both the T1 and T2 questionnaire, leaving a final sample of 298 individuals (227 women, $71 \mathrm{men})$. Participants ranged in age from 21 to 62 years $(M=26.00, S D=6.57)$.

\section{Measures}

The questionnaire included measures of social well-being and conservation behavior with sociodemographic questions (gender, age, education, and income). Table 1 displays the descriptive statistics and reliability of the social well-being and conservation behavior scales. For each scale, a latent variable was defined.

Table 1. Descriptive statistics, reliability estimates, and correlations among the study variables

\begin{tabular}{|l|c|c|c|c|c|c|c|c|c|}
\hline Study variables & $\mathbf{M}$ & $\mathrm{SD}$ & $\mathbf{a}$ & $\mathrm{CR}$ & $\mathbf{1}$ & $\mathbf{2}$ & $\mathbf{3}$ & $\mathbf{4}$ & $\mathbf{5}$ \\
\hline 1. Gender & - & - & - & - & - & -.09 & -.06 & $.15^{\star}$ & $.13^{\star}$ \\
\hline 2. Social well-being (T1) & 2.87 & 0.70 & .89 & .90 & & - & $.69^{\star}$ & $.20^{\star}$ & $.22^{\star}$ \\
\hline 3. Social well-being (T2) & 2.81 & 0.71 & .91 & .92 & & & - & $.25^{\star}$ & $.28^{\star}$ \\
\hline 4. Pro-environmental behavior (T1) & 4.22 & 1.23 & .70 & .80 & & & & - & $.75^{\star}$ \\
\hline 5. Pro-environmental behavior (T2) & 4.11 & 1.26 & .76 & .84 & & & & & - \\
\hline
\end{tabular}

Note. $\mathrm{N}=$ 298. $M=$ mean, $S D=$ standard deviation, $C R=$ composite reliability. For gender, $1=$ male, 2 = female. ${ }^{*} p<.05$.

\section{Conservation behavior}

The conservation scale of the pro-environmental behavior scale (Markle, 2013) was used in this study to measure actual energy conservation behaviors (related to curtailment). This scale was chosen because it was found to have good psychometric properties and to cover different aspects of energy conservation behavior. The conservation scale includes seven items concerning the extent to which participants in the last month reduced their consumption of energy. All items were answered on a 5 -point Likert-type scale $(1=$ never, $2=$ rarely, $3=$ sometimes, $4=$ usually, $5=$ always). The seven items of the scale are: 
- How often do you turn off the lights when leaving a room?

- How often do you switch off standby modes of appliances or electronic devices?

- How often do you cut down on heating or air conditioning to limit energy use?

- How often do you turn off the TV when leaving a room?

- How often do you limit your time in the shower in order to conserve water?

- How often do you wait until you have a full load to use the washing machine or dishwasher?

- How often do you wash your laundry at a lower temperature?

\section{Social well-being}

The Italian version of the social well-being scale (Cicognani et al., 2008; Keyes, 1998) was used to measure social well-being. We chose this scale because: (a) this is the most widely used scale of social well-being; (b) it was found to have good psychometric properties; and (c) an Italian version was available. The scale included 33 items that participants rated on a 7 -point scale $(1=$ strongly disagree, $2=$ disagree, 3 = somewhat disagree, 4 = neither agree nor disagree, $5=$ somewhat agree, $6=$ agree, 7 = strongly agree) to indicate how an item functioned in their social life. Negative items were reverse-coded. The scale included items related to social integration ("I feel close to other people in my community"), social acceptance ("People do not care about other peoples' problems"), social coherence ("I cannot make sense of what's going on in the world"), social contribution ("My daily activities do not create anything worthwhile for my community"), and social actualization ("Society isn't improving for people like me").

\section{Procedure}

To collect data, we used a website accessible only to participants. Participants were asked to read a consent form that explained the procedures of the study and their rights as participants (e.g., the voluntary and confidential nature of participation). Participants then filled out the questionnaire at their convenience. Two months later, participants completed a second questionnaire. Participants were contacted through the email address they had previously provided. We chose a two-month period because we could be properly sure that courses that participants were taking did not have an impact on our study. Moreover, within that period, in Italy, no major event occurred that could have affected our findings. Finally, a two-month followup may be justified since the predominant causal influence between determinants of pro-environmental outcomes and related outcomes is supported in a short-term perspective (Thøgersen \& Ölander, 2002). 


\section{Statistical analysis}

Missing data estimation was employed using maximum likelihood imputation procedure as recommended by Graham (2009). To measure reliability, we calculated composite reliability (Fornell \& Larcker, 1981) in addition to Cronbach's alpha, because it is considered a lower bound on true reliability (Raykov, 1997). Both coefficients were calculated and reported. Cross-lagged path analysis was conducted using Mplus version 7 (Muthén \& Muthén, 1998-2012). The WLSMV estimator (a robust weighted least squares estimator using a diagonal weight matrix) was used because of violation of the assumption of multivariate normality (DeCarlo, 1997). To test our hypotheses using a structural model, we included the following parameters: covariance among the latent variables; covariance between error terms of each indicator at $\mathrm{T} 1$ and the corresponding indicator at T2; auto-regressive effects (to control for baseline levels for each variable); and cross-lagged relationships to test the hypotheses (Cole \& Maxwell, 2003). In the model we controlled for the effect of age and income. We did not include education in the model because it showed almost no variability.

\section{Results}

\section{Preliminary analyses}

Table 1 shows correlations and descriptive statistics for the study variables. The point biserial correlation coefficients show that gender did not correlate with social well-being, but gender (female) was positively associated with conservation behavior. Social well-being correlated positively with conservation behavior both synchronously and over time. The effect size of the correlations between social well-being at T1 and conservation behavior at T2 and between conservation behavior at T1 and social well-being at T2 is of medium magnitude (Cohen, 1988). Moreover, the correlations between social well-being and T1 and at T2 and between conservation behavior at $\mathrm{T} 1$ and at $\mathrm{T} 2$ were .69 and .75 , respectively.

\section{Tests of hypotheses}

Figure 1 shows the hypothesized cross-lagged path model. The fit of the model was acceptable $\left(\chi^{2}(275)=514.50, p<0.001\right.$; NNFI $=0.90$; CFI $=0.92$; RMSEA $=0.054)$. Consistent with our first hypothesis, individuals' own baseline levels of conservation behavior predicted follow-up social well-being controlling for the effects of baseline social well-being. In line with our second hypothesis, social wellbeing at $\mathrm{T} 1$ predicted subsequent levels of conservation behavior controlling for baseline levels of social well-being. Therefore, both hypotheses were confirmed. The model explains 67 per cent of the variance in both social well-being and 
conservation behavior at T2. The standardized parameters are reflective of the proportion of unique explained variance in an outcome variable per independent variable. The standardized path coefficients (i.e., beta values) show that social wellbeing at $\mathrm{T} 1$ accounts for a small but significant proportion of the explained variance of conservation behavior at T2. Also, conservation behavior at T1 accounts for a small but significant proportion of the explained variance of social well-being at $\mathrm{T} 2$.

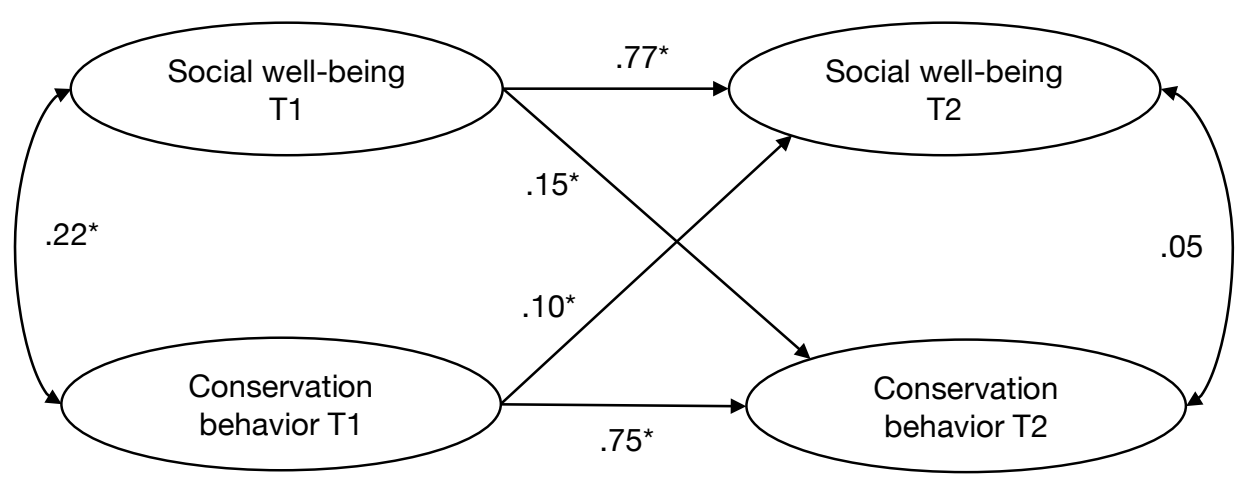

Figure 1. Cross-lagged relationships between social well-being and proenvironmental behavior at Time 1 and Time 2

Note. $X^{2}(275)=514.50, p<0.001 ; \mathrm{NNFI}=0.90 ; \mathrm{CFI}=0.92$; RMSEA $=0.054$. Regression coefficients are standardized. ${ }^{\star} p<.05$. The influence of age and income was controlled for.

\section{Testing model invariance by gender}

We tested for multi-group invariance to investigate whether differences between female and male participants existed with respect to the hypothesized cross-lagged relationships. Comparison of a model in which all the cross-lagged relationships were constrained equal across groups and one in which no constraints were imposed yielded a $\Delta \chi^{2}$ value of 0.69 with $\Delta d f=2(p=.71)$. The statistically nonsignificant $\Delta \chi^{2}$ value suggests that the cross-lagged relationships are equivalent across male and female participants.

\section{Discussion}

Our goal was to investigate the relationship between social well-being and conservation behavior. Although conservation behavior is often framed in terms of sacrifice and reduced well-being (e.g., Carmi, 2012; De Young, 1990), there is evidence that well-being and conservation behavior may be compatible or complementary (e.g., Brown \& Kasser, 2005; Corral-Verdugo et al., 2011; Dietz et al., 2009; Venhoeven et al., 2013; Xiao \& Li, 2011). We extended this reasoning further, and suggested that a relationship also exists between social well-being and 
conservation behavior and that it may be bidirectional. Our findings confirmed the hypothesized bidirectional relationship: on one hand, conservation behavior predicted social well-being and, on the other hand, social well-being predicted conservation behavior.

The finding that conservation behavior was significantly associated with later social well-being, after controlling for previous levels of social well-being, suggests that conservation behavior could promote well-being. This finding is in line with the idea that acting pro-environmentally actually increases one's well-being rather than decreases one's well-being; in other words, doing "the right thing" for the environment, for the earth, and for human beings makes people feel good (e.g., Brown \& Kasser, 2005; Suárez-Varela et al., 2016; Venhoeven et al., 2013; Xiao \& Li, 2011). Our study contributes to and builds upon existing research on conservation behavior and well-being in that we examined the effect of social well-being. Based on the mental health continuum model (Keyes, 2002, 2003), well-being is defined as including three correlated but distinct factors: emotional, psychological, and social well-being. To our knowledge, social well-being (a category of eudaemonic well-being) had never been investigated in respect to conservation behavior. It is interesting to note that conservation behavior predicted social well-being even though our measure did not take into account the meaning associated with the behavior (i.e., "it is the right thing to do"). Indeed, Venhoeven et al. (2013) suggested for pro-environmental behavior to theoretically increase eudaemonic well-being, it is important to consider the extent to which people see pro-environmental behavior as the right thing to do. In Europe, there is solid and widespread support for protection of the environment (European Commission, 2014) and, therefore, it is likely that pro-environmental behavior may be perceived by most people as right and meaningful. As such, proenvironmental behavior can be framed as a normative goal that has an intrinsic positive moral value (Steg, Bolderdijk et al., 2014). Put differently, the well-being benefits of pro-environmental behavior depend on a favorable assessment of the rewards associated with it: rewards could derive from social identity or from the opportunity to view oneself in more positive terms (i.e., "I am the kind of person who takes right actions"). Being confident of one's ability to achieve the things that make a difference and forge a better life is one of the most important motivations hypothesized in the Reasonable Person Model of environmentally responsible behavior (Kaplan, 2000; Kaplan \& Kaplan, 2003, 2008).

In addition, the specific features of social well-being would also explain this finding. Precisely, social well-being includes the evaluation of one's social value and contribution to society, the perception of the quality of the relationship between the individual and the society, and the view of human nature and society. Therefore, pro-environmental behavior is likely to influence the appraisal of one's circumstance and functioning in society, that is, social well-being. We do not deny that pro-environmental behavior can require, at least to some extent, sacrifice and 
deprivation. However, once learned, pro-environmental behavior may be activated in an automatic, habitual fashion with low perceived costs associated with the behavior, while benefits remain the same. In our investigation, previous conservation behavior had a strong effect on actual conservation behavior, thereby suggesting the development of a habit. Voluntary simplicity is another variable that may be of interest here. Voluntary simplicity refers to a wide range of beliefs systems and practices that aim to limit material consumption due to self-centered (e.g., to free one's resources such as money and time) and/or altruistic (e.g., concern for the environment and social justice) considerations (Shaw \& Newholm, 2002).

Our findings are in line with those of Son and Wilson (2012), who demonstrated a reciprocal relationship between well-being and pro-social behavior. Based on the idea that pro-environmental behavior is a form of pro-social behavior (Steg $\&$ de Groot, 2010; Turaga et al., 2010; Venhoeven et al., 2013), we hypothesized and found that social well-being predicts conservation behavior. This idea overturns the common perspective from which the relationship between conservation behavior and well-being is usually considered (i.e., conservation behavior is a predictor of social well-being). To our knowledge, this is the first attempt to measure the influence of well-being on conservation behavior using a cross-lagged panel design. The finding that well-being influenced conservation behavior is in line with the suggestion that a positive feedback loop exists between conservation behavior and well-being (Corral-Verdugo et al., 2011) and with the social outlook hypothesis (Carlson et al., 1988). Specifically, the positive mood associated with a favorable view of one's circumstance and functioning in society is likely to increase pro-social and pro-environmental behavior. People who feel good as a consequence of their efforts to pursue meaning in life and contribute to society can shift their focus from satisfaction and happiness associated with personal wealth and possessions to satisfaction associated with doing something good for their environment and their community. This shift in focus can provide meaning in life and reinforce a valuable social identity (Venhoeven et al., 2013). Put another way, eudaemonic well-being is likely to lead people to invest more time and effort in the pursuit of more intrinsic and non-materialistic goals such as the protection of the environment. Another, non-alternative, possibility is based on the norm of reciprocity (Gouldner, 1960). Specifically, individuals who see themselves thriving in their social life may have a tendency to reciprocate society's support and care for them by enacting proenvironmental behavior.

The finding that conservation behavior is affected by high social well-being has practical implications which warrant consideration. According to Steg, Bolderdijk, et al. (2014), pro-environmental actions can be promoted by explicitly emphasizing that conservation behaviors are good choices not only for the environment, they also make people feel good (hedonic goal), by increasing their resources (gain goal) and enhancing their status, offering them the opportunity to enter into a "moral right" 
community (normative goal). Interventions that link hedonic and gain goals to normative goals should be more effective at promoting pro-environmental choices than those targeting single goals (Steg, Bolderdijk et al., 2014).

However, well-being, and in particular social well-being, is not only inside people's heads. It is influenced by people's values and goals but is nurtured by real-life opportunities to experience trustworthy relationships, and a sense of connectedness with people. This set of opportunities can be considered as part of social capital (Putnam, 1993; Putnam et al., 1993). Many empirical studies have shown that social capital has an impact on pro-environmental behaviors (Jones, 2010; Liu et al., 2014; Pretty \& Ward, 2001) contributing to the environmental activation of the community. We speculate that social well-being could be one of the key processes that explains this impact. In addition, a role in the promotion of ecologically and socially sustainable societies is played by citizen involvement in the wider community and its social institutions, as it is implied in the concept of community participation (e.g., Bott et al., 2003; Dean \& Bush, 2007; Prati et al., 2016). As such, interventions aimed at promoting pro-environmental choices should not only strengthen the added value and psychological gains of becoming part of a righteous community, but also offer concrete opportunities to experience community participation. Future work should investigate the influence of interventions aimed at promoting proenvironmental behavior on social well-being and whether such interventions are more effective when opportunities to experience a sense of community are provided.

A few limitations of the present study deserve mention. First, although the crosslagged panel design provides a much stronger indication of the direction of the relationships than is possible with a cross-sectional study, it does not provide definitive answers to the question of causality. Experimental studies are needed to confirm the hypothesized causal relationships. Second, given that our sample comprised students, the findings may be limited by age or occupation and we cannot generalize our findings to the general population. We note that our results were consistent between male and female participants, indicating that gender does not affect the hypothesized relationships; future work should integrate other variables influencing environmental behavior to identify the unique role of social well-being (and its dimensions) in comparison to these other commonly cited predictors. Nonetheless, these findings need to be replicated in other samples to evaluate their theoretical and practical significance. Moreover, the use of self-reports has known limitations. Finally, we did not measure potentially confounding variables that might relate to both of the measured variables. For instance, self-construal, locus of control, values, attitudes, goals, and felt responsibility are thought to exert an influence on pro-environmental behavior (Gifford \& Nilsson, 2014). As the literature suggests, behavior is a complex factor and the attempt to explain pro-environmental behavior can also be quite complex. We must recognize that our study provides one piece of 
the complex puzzle of social well-being and energy conservation behavior. After all, the main aim of the present study was to shed light on bidirectional relationships between social well-being and energy conservation behavior.

\section{Conclusion}

Overall, our findings fill an important gap in the literature by showing that a bidirectional relationship between social well-being and conservation behavior exists. In addition, these relationships were demonstrated through a cross-lagged design. The findings of the current study may help tailor future interventions that are aimed at increasing conservation behavior and well-being.

\section{References}

Aknin, L., Dunn, E., \& Norton, M. (2012). Happiness runs in a circular motion: Evidence for a positive feedback loop between prosocial spending and happiness. Journal of Happiness Studies, 13(2), 347-355. doi.org/10.1007/ s10902-011-9267-5

Bott, S., Cantrill, J. G., \& Myers, O. E., Jr. (2003). Place and the promise of conservation psychology. Human Ecology Review, 10(2), 100-112.

Brown, K., \& Kasser, T. (2005). Are psychological and ecological well-being compatible? The role of values, mindfulness, and lifestyle. Social Indicators Research, 74(2), 349-368. doi.org/10.1007/s11205-004-8207-8

Carlson, M., Charlin, V., \& Miller, N. (1988). Positive mood and helping behavior: A test of six hypotheses. Journal of Personality and Social Psychology, 55(2), 211-229. doi.org/10.1037/0022-3514.55.2.211

Carmi, N. (2012). Caring about tomorrow: Future orientation, environmental attitudes and behaviors. Environmental Education Research, 19(4), 430-444. doi.org/10.1080/13504622.2012.700697

Choi, J.-S. (2008). Characteristics of community life in foreign intentional communities focus on the differences between ecovillage and cohousing. International Journal of Human Ecology, 9(2), 93-105.

Cicognani, E., Pirini, C., Keyes, C., Joshanloo, M., Rostami, R., \& Nosratabadi, M. (2008). Social participation, sense of community and social well being: A study on American, Italian and Iranian university students. Social Indicators Research, 89(1), 97-112. doi.org/10.1007/s11205-007-9222-3 
Clayton, S., \& Myers, G. (2015). Conservation psychology: Understanding and promoting human care for nature. Chichester, UK: Wiley-Blackwell.

Cloutier, S., Larson, L., \& Jambeck, J. (2014). Are sustainable cities “happy” cities? Associations between sustainable development and human well-being in urban areas of the United States. Environment, Development and Sustainability, 16(3), 633-647. doi.org/10.1007/s10668-013-9499-0

Cohen, J. (1988). Statistical power analysis for the behavioral sciences (2nd ed.). Hillsdale, NJ: Erlbaum.

Cole, D. A., \& Maxwell, S. E. (2003). Testing mediational models with longitudinal data: Questions and tips in the use of structural equation modeling. Journal of Abnormal Psychology, 112(4), 558-577. doi.org/10.1037/0021-843X.112.4.558

Corral-Verdugo, V., Mireles-Acosta, J., Tapia-Fonllem, C., \& Fraijo-Sing, B. (2011). Happiness as correlate of sustainable behavior: A study of pro-ecological, frugal, equitable and altruistic actions that promote subjective wellbeing. Human Ecology Review, 18(2), 95-104.

Dean, J. H., \& Bush, R. A. (2007). A community psychology view of environmental organization processes. American Journal of Community Psychology, 40(1-2), 146-166. doi.org/10.1007/s10464-007-9123-2

DeCarlo, L. T. (1997). On the meaning and use of kurtosis. Psychological Methods, 2(3), 292-307. doi.org/10.1037/1082-989X.2.3.292

De Young, R. (1990). Some psychological aspects of living lightly: Desired lifestyle patterns and conservation behavior. Journal of Environmental Systems, 20(3), 215-227. doi.org/10.2190/030Q-Q4KE-7YFB-4Q0F

Dietz, T., Rosa, E. A., \& York, R. (2009). Environmentally efficient well-being: Rethinking sustainability as the relationship between human well-being and environmental impacts. Human Ecology Review, 16(1), 114-123.

European Commission. (2014). Attitudes of European citizens towards the environment. Special Eurobarometer 416/Wave EB81.3. Retrieved from ec.europa.eu/public_opinion/archives/ebs/ebs_416_en.pdf

Fornell, C., \& Larcker, D. F. (1981). Evaluating structural equation models with unobservable variables and measurement error. Journal of Marketing Research, 18(1), 39-50. doi.org/10.2307/3151312 
Fröhlich, G., Sellmann, D., \& Bogner, F. X. (2012). The influence of situational emotions on the intention for sustainable consumer behaviour in a studentcentred intervention. Environmental Education Research, 19(6), 747-764. doi.org/10.1080/13504622.2012.749977

Ganglmair-Wooliscroft, A., \& Wooliscroft, B. (2016). Ethical holiday behavior, wellbeing and orientations to happiness. Applied Research in Quality of Life, 11(1), 83-103.

Gifford, R., \& Nilsson, A. (2014). Personal and social factors that influence pro-environmental concern and behaviour: A review. International Journal of Psychology, 49(3), 141-157. doi.org/10.1002/ijop.12034

Gouldner, A. W. (1960). The norm of reciprocity: A preliminary statement. American Sociological Review, 25(2), 161-178. doi.org/10.2307/2092623

Graham, J. W. (2009). Missing data analysis: Making it work in the real world. Annual Review of Psychology, 60(1), 549-576. doi.org/10.1146/annurev. psych.58.110405.085530

Helliwell, J. F. (2014). Social norms, happiness, and the environment: Closing the circle. Sustainability: Science, Practice, \& Policy, 10(1). Retrieved from sspp. proquest.com/social-norms-happiness-and-the-environment-closing-the-circle440f38ff30c4\#.wt9gwoa01

Hunter, L. M., Hatch, A., \& Johnson, A. (2004). Cross-national gender variation in environmental behaviors. Social Science Quarterly, 85(3), 677-694. doi.org/ 10.1111/j.0038-4941.2004.00239.x

IPCC (Intergovernmental Panel on Climate Change). (2014). Climate change 2014: Mitigation of climate change. Contribution of working group III to the fifth assessment report of the IPCC. Cambridge: Cambridge University Press.

Jones, N. (2010). Environmental activation of citizens in the context of policy agenda formation and the influence of social capital. The Social Science Journal, 47(1), 121-136. doi.org/10.1016/j.soscij.2009.05.008

Kaplan, S. (2000). New ways to promote proenvironmental behavior: Human nature and environmentally responsible behavior. Journal of Social Issues, 56(3), 491-508. doi.org/10.1111/0022-4537.00180

Kaplan, S., \& Kaplan, R. (2003). Health, supportive environments, and the Reasonable Person Model. American Journal of Public Health, 93(9), 1484-1489. doi.org/10.2105/AJPH.93.9.1484 
Kaplan, S., \& Kaplan, R. (2008). Health, supportive environments, and the Reasonable Person Model. In J. M. Marzluff, E. Shulenberger, W. Endlicher, M. Alberti, G. Bradley, C. Ryan, U. Simon, \& C. ZumBrunnen (Eds.), Urban ecology: An international perspective on the interaction between humans and nature (pp. 557-565). Boston, MA: Springer. doi.org/10.1007/978-0-387-73412-5_36

Keyes, C. L. M. (1998). Social well-being. Social Psychology Quarterly, 61(2), 121-140. doi.org/10.2307/2787065

Keyes, C. L. M. (2002). The mental health continuum: From languishing to flourishing in life. Journal of Health and Social Behavior, 43(2), 207-222. doi.org/10.2307/3090197

Keyes, C. L. M. (2003). Complete mental health: An agenda for the 21 st century. In C. L. M. Keyes \& J. Haidt (Eds.), Flourishing: Positive psychology and the life well-lived (pp. 293-312). Washington, DC: American Psychological Association. doi.org/10.1037/10594-013

Keyes, C. L. M. (2004). Social well-being in the United States: A descriptive epidemiology. In O. G. Brim, C. D. Ryff, \& R. Kessler (Eds.), How healthy are we? A national study of well-being at midlife (pp. 350-372). Chicago, IL: University of Chicago Press.

Larson, J. S. (1993). The measurement of social well-being. Social Indicators Research, 28(3), 285-296. doi.org/10.1007/BF01079022

Liu, J., Qu, H., Huang, D., Chen, G., Yue, X., Zhao, X., \& Liang, Z. (2014). The role of social capital in encouraging residents' pro-environmental behaviors in community-based ecotourism. Tourism Management, 41, 190-201. doi.org/ 10.1016/j.tourman.2013.08.016

Markle, G. (2013). Pro-environmental behavior: Does it matter how it's measured? Development and validation of the pro-environmental behavior scale (PEBS). Human Ecology, 41(6), 905-914. doi.org/10.1007/s10745-013-9614-8

Muthén, L. K., \& Muthén, B. O. (1998-2012). Mplus user's guide (7th ed.). Los Angeles, CA: Muthén \& Muthén.

Nolan, J. M., \& Schultz, P. W. (2015). Prosocial behavior and environmental action. In D. A. Schroeder \& W. G. Graziano (Eds.), The Oxford handbook of prosocial behavior (pp. 626-652). Oxford: Oxford University Press.

O’Brien, C. (2008). Sustainable happiness: How happiness studies can contribute to a more sustainable future. Canadian Psychology/Psychologie Canadienne, 49(4), 289-295. doi.org/10.1037/a0013235 
Podsakoff, P. M., MacKenzie, S. B., \& Podsakoff, N. P. (2012). Sources of method bias in social science research and recommendations on how to control it. Annual Review of Psychology, 63(1), 539-569. doi.org/10.1146/annurev-psych120710-100452

Prati, G., Albanesi, C., Pietrantoni, L., \& Airoldi, L. (2016). Public perceptions of beach nourishment and conflict management strategies: A case study of Portonovo Bay in the Adriatic Italian Coast. Land Use Policy, 50, 422-428. doi.org/10.1016/j.landusepol.2015.06.033

Pretty, J., \& Ward, H. (2001). Social capital and the environment. World Development, 29(2), 209-227. doi.org/10.1016/S0305-750X(00)00098-X

Putnam, R. D. (1993). The prosperous community: Social capital and public life. The American Prospect, 13, 35-42.

Putnam, R. D., Leonardi, R., \& Nanetti, R. Y. (1993). Making democracy work: Civic traditions in modern Italy. Princeton, NJ: Princeton University Press.

Raykov, T. (1997). Estimation of composite reliability for congeneric measures. Applied Psychological Measurement, 21(2), 173-184. doi.org/10.1177/ 01466216970212006

Ryff, C., \& Keyes, C. L. M. (1995). The structure of psychological well-being revisited. Journal of Personality and Social Psychology, 69(4), 719-727. doi.org/ 10.1037/0022-3514.69.4.719

Sanguinetti, A. (2012). The design of intentional communities: A recycled perspective on sustainable neighborhoods. Behavior and Social Issues, 21, 5-25. doi.org/10.5210/bsi.v21i0.3873

Saunders, C. D. (2003). The emerging field of conservation psychology. Human Ecology Review, 10(2), 137-149.

Schultz, P. W., \& Zelezny, L. (1999). Values as predictors of environmental attitudes: Evidence for consistency across 14 countries. Journal of Environmental Psychology, 19(3), 255-265. doi.org/10.1006/jevp.1999.0129

Shaw, D., \& Newholm, T. (2002). Voluntary simplicity and the ethics of consumption. Psychology and Marketing, 19(2), 167-185. doi.org/10.1002/ mar. 10008

Son, J., \& Wilson, J. (2012). Volunteer work and hedonic, eudemonic, and social well-being. Sociological Forum, 27(3), 658-681. doi.org/10.1111/j.15737861.2012.01340.x 
Steg, L., Bolderdijk, J. W., Keizer, K., \& Perlaviciute, G. (2014). An integrated framework for encouraging pro-environmental behaviour: The role of values, situational factors and goals. Journal of Environmental Psychology, 38, 104-115. doi.org/10.1016/j.jenvp.2014.01.002

Steg, L., \& de Groot, J. (2010). Explaining prosocial intentions: Testing causal relationships in the norm activation model. British Journal of Social Psychology, 49(4), 725-743. doi.org/10.1348/014466609X477745

Steg, L., Perlaviciute, G., van der Werff, E., \& Lurvink, J. (2014). The significance of hedonic values for environmentally relevant attitudes, preferences, and actions. Environment and Behavior, 46(2), 163-192. doi.org/10.1177/ 0013916512454730

Stem, C. J., Lassoie, J. P., Lee, D. R., Deshler, D. D., \& Schelhas, J. W. (2003). Community participation in ecotourism benefits: The link to conservation practices and perspectives. Society \& Natural Resources, 16(5), 387-413. doi.org/ $10.1080 / 08941920309177$

Suárez-Varela, M., Guardiola, J., \& González-Gómez, F. (2016). Do proenvironmental behaviors and awareness contribute to improve subjective wellbeing? Applied Research in Quality of Life, 11(2), 429-444.

Thøgersen, J., \& Ölander, F. (2002). Human values and the emergence of a sustainable consumption pattern: A panel study. Journal of Economic Psychology, 23(5), 605-630. doi.org/10.1016/S0167-4870(02)00120-4

Turaga, R. M., Howarth, R. B., \& Borsuk, M. E. (2010). Pro-environmental behavior: Rational choice meets moral motivation. Annals of the New York Academy of Sciences, 1185, 211-224. doi.org/10.1111/j.1749-6632.2009.05163.x

Venhoeven, L. A., Bolderdijk, J. W., \& Steg, L. (2013). Explaining the paradox: How pro-environmental behaviour can both thwart and foster well-being. Sustainability, 5, 1372-1386. doi.org/10.3390/su5041372

Villacorta, M., Koestner, R., \& Lekes, N. (2003). Further validation of the motivation toward the environment scale. Environment and Behavior, 35(4), 486-505. doi.org/10.1177/0013916503035004003

Xiao, J., \& Li, H. (2011). Sustainable consumption and life satisfaction. Social Indicators Research, 104(2), 323-329. doi.org/10.1007/s11205-010-9746-9

Zelezny, L. C., Chua, P.-P., \& Aldrich, C. (2000). New ways of thinking about environmentalism: Elaborating on gender differences in environmentalism. Journal of Social Issues, 56(3), 443-457. doi.org/10.1111/0022-4537.00177 
This text is taken from Human Ecology Review, Volume 23, Number 1, 2017, published 2017 by ANU Press, The Australian National University, Canberra, Australia.

dx.doi.org/10.22459/HER.23.01.2017.07 